\title{
Adversidades no fazer antropológico
}

Refletir sobre o trabalho de campo no ofício antropológico é pensar, quase sempre, em desafios. Estudar pessoas, grupos e fenômenos próximos ou distantes é um processo reflexivo e político constantemente tensionado, de modo que os desafios nele contidos estão associados às especificidades de cada campo e, também, de cada antropóloga e antropólogo. Embora a pesquisa de campo seja um momento de profundo aprendizado, são escassas as discussões analíticas sobre possíveis adversidades, riscos e abusos, sobretudo as que se debruçam metodologicamente sobre os corpos marcados na relação antropológica em campo. Nesse escopo, se ir a campo é um movimento fundamental na produção do conhecimento e do próprio fazer antropológico, ele ainda tende a ser romantizado por diversos autores em textos e manuais clássicos de antropologia.

A partir dessa questão formulamos esta Seção Especial, inspirada na discussão metodológica e epistemológica incitada no texto Rape in The Field: reflections from a survivor (MORENO, 1995). ${ }^{1}$ Neste artigo, a antropóloga, que optou por utilizar um pseudônimo, descreve e analisa uma série de eventos abusivos vivenciados por ela durante seu trabalho de campo na Etiópia. Os abusos cometidos por seu então assistente de campo perpassam questionamentos da sua autoridade enquanto pesquisadora, assédios, jogos psicológicos, estupro à mão armada e ameaças. Questões que vão desde os efeitos produzidos na realização do trabalho de campo até a negociação na publicação dos eventos ocorridos abrem espaço para uma discussão acerca das consequências éticas e políticas dos escritos antropológicos. Os efeitos dessas adversidades ultrapassam o campo propriamente dito, alcançando a produção e circulação do conhecimento produzido.

Portanto, a proposta desta Seção Especial teve como objetivo proporcionar um espaço de debates sobre as adversidades encontradas em campo e como elas influem sobre os caminhos e formas que nossas pesquisas tomam, na intenção de explorar a diversidade de experiências em campo. Ao discutir questões que atravessam os fazeres antropológicos recebemos textos variados que remetem a temas como engajamento antropológico, enfrentamento da burocracia, impedimentos e/ou negociações necessárias à realização do trabalho, assédios vivenciados em campo, questões éticas e metodológicas implicadas durante e

\footnotetext{
${ }^{1}$ Outros textos que debatem, sob outro ângulo, a presença de mulheres em campo e seus desdobramentos na pesquisa: Woman in the field, coletânea de 1970; Cidade de Mulheres. Agradecemos a Professora Heloísa Buarque de Almeida por nos recordar dess bibliografia durante sua fala na palestra Sexta do Mês.
} 
após a realização de pesquisas, entre outras temáticas sensíveis à relação entre antropóloga/o, campo e sujeitos pesquisados.

Dessa forma, com os textos que apresentaremos a seguir, buscamos trazer elementos, que não esgotam, mas que dialogam com questionamentos que colocam as adversidades do fazer antropológico em campo. Quais os efeitos dos corpos de antropólogas e antropólogos nas interações que são estabelecidas entre os grupos com os quais interagem? Ao refletir sobre a própria entrada em campo, marcada por "hierarquias articuladas" ([1995], p. 224) a autora incita a questão: quais são as marcações - como as de raça, de classe, de gênero, de sexualidade, de geração, de deficiência - que são percebidas em campo, e de que forma se articulam e conformam caminhos diversos nas relações travadas em campo? Quais estratégias textuais podem ser pensadas como forma de inserir analiticamente situações de adversidade do trabalho de campo e quais seus rendimentos para uma reflexão analítica sobre a propriedade de conceitos e de métodos empregados pela Antropologia? Como lidamos com situações de desigualdade e assimetria entre poderes e agências que constituem o modo como pesquisadoras e pesquisadores experimentam e descrevem os mundos sociais dos quais participam? Essas foram algumas das questões que nortearam os escritos das pessoas que submeteram seus textos.

Fazer a seleção para compor esse Especial não foi uma tarefa simples, tanto pelo volume de textos que recebemos, quanto pelas reflexões propostas que nos mobilizam como pessoas e antropólogas. Nos surpreendemos com a adesão à proposta e ficamos muito contentes com os textos que conseguiram articular experiências pessoais com questões metodológicas, trazendo reflexões sobre suas inserções em campo, marcadas de formas variadas, mas sempre esboçando a necessidade da reflexividade de todo o fazer antropológico. Desta forma, pela quantidade de textos recebidos que se adequaram à proposta do Especial, a seção terá continuidade no segundo volume da edição 26 da revista.

Para essa primeira parte foram escolhidos sete textos, sem nenhum critério classificatório, na tentativa de buscar um balanceamento das temáticas para os dois volumes, uma composição que apresentasse um leque variado de adversidades encontradas em campo. Julgamos que seria interessante para a leitura, não com intuito de dar conta da complexidade do trabalho de campo, explorar pluralidades do fazer etnográfico. O primeiro texto, de Victor Hugo Barreto, propõe uma etnografia das reações aos trabalhos sobre sexualidade publicados pelo autor. Perpassa discussões metodológicas acerca de pesquisas sobre sexo e práticas sexuais. $\mathrm{O}$ artigo aborda também desconfianças, desconfortos e invalidações por parte de pares da academia, diante dos seus temas, pela especificidade da abordagem etnográfica em relação a sexo e sexualidade, não entendidas como temáticas legítimas de serem pesquisadas e abordadas antropologicamente. 
O relato de Karina Biondi ${ }^{2}$ apresenta os percalços do início da pesquisa na quebrada, relativo à, dentre outros fatores, invisibilidade do PCC (Primeiro Comando da Capital, objeto de estudo da autora há anos). Também mostra o quanto o estabelecimento de contatos e formação de vínculo com interlocutores não é algo fácil de obter. Há também momentos de perguntar e outros de calar, que a pesquisadora também precisou aprender. Contudo, essas adversidades podem levar à compreensão de certas dinâmicas internas ao objeto da pesquisa, antes imperceptíveis. Estratégias para a viabilidade da pesquisa podem ser alteradas e até mesmo levar à reformulação das hipóteses.

O corpo feminino e negro em campo tem suas peculiaridades. As adversidades em sua marcação não foram fáceis de contornar em sua pesquisa na Itália. Através da narrativa de momentos passados em campo, Fabiane Albuquerque proporciona reflexões metodológicas sobre as possibilidades de abordagem e acesso das pessoas em Veronetta. Ainda sobre corpo negro, mas noutra circunstância de pesquisa, Flávia Medeiros traz questões relevantes sobre lugar de fala, feminismo negro, e suas implicações no trabalho de campo. Esse texto trata do tema da proximidade entre pesquisadora e pesquisados, pois a autora mora próximo ao local onde realiza sua etnografia, compartilha de experiências de sociabilidade nos mesmos locais, ao mesmo tempo em que leva em conta a distância de opiniões, os conflitos internos em lidar com certas percepções e atitudes dos policiais pesquisados.

Maycon Lopes, através de seus dados etnográficos, conduz uma reflexão importante, traz dados etnográficos para a discussão da experiência do antropólogo em campo e tematiza as adversidades em relação às questões éticas vivenciadas pelo pesquisador em contextos violentos e em relação ao uso devido/indevido da fotografia, balizado por demais etnografias, mobilizando uma boa discussão teórica sobre o assunto. Seguindo a linha da variedade temática que não está livre de adversidades, Lucia Meneses aborda de maneira relevante não só os desafios do trabalho de campo, mas temas como religião, gênero, antropologia e ética. $\mathrm{O}$ texto destaca-se pelo modo como a autora se coloca em campo e reflete sobre sua presença no cotidiano dos sujeitos de sua pesquisa e também como mobiliza diversas autoras e autores que refletem sobre grupos religiosos e problemas éticos em pesquisas sobre religião.

\footnotetext{
${ }^{2} \mathrm{O}$ evento intitulado "Risco e Vulnerabilidade em campo", foi realizado em setembro de 2017 na USP e está disponível no canal Sexta do Mês do Youtube (https://www.youtube.com/ watch?v=7nKNznUM510). Karina Biondi foi uma das convidas à palestra e, por conseguinte, convidada a enviar seu texto a esse especial. Tanto a palestra como o dossiê foram desdobramentos de um debate ocorrido em sala de aula, durante o curso de Metodologia de Projeto para alunos de doutorado, ministrado pelo professor Heitor Frúgoli, no primeiro semestre de 2017. Agradecemos ao professor pelo espaço para discussão e apoio para o prosseguimento da discussão do tema.
} 
Por fim, um texto de engajamento coletivo em sua produção chamou atenção pelo seu potencial para auxiliar novas pesquisadoras e pesquisadores em suas jornadas. As cinco autoras, Caroline Cotta de Mello Freitas, Rafaela N. Pannain, Heloisa M. Gimenez, Sue Iamamoto, Aiko Ikemura Amaral, promovem descrições sobre a posição da mulher pesquisadora, complementados de relatos pessoais e coletivos. Salientam a falta de discussão sobre gênero em campo e seus impactos na pesquisa, trazendo questões para serem pensadas antes, durante e depois do trabalho etnográfico. Através desses sete textos, pretendemos alcançar uma composição coerente à proposta do Especial e profícua ao debate sobre o fazer etnográfico.

Além dos textos recebidos, esse dossiê conta também com a tradução do texto que o motivou. Nossa movimentação coletiva para traduzi-lo resultou e refletiu um trabalho intenso - e gostaríamos de agradecer a generosidade de Thais H. Tiriba por ter colaborado conosco nesta empreitada. O trabalho de tradução do texto, desde seu título, nos arrebatou de questionamentos sobre a marcação de gênero das palavras, que também apontavam para a imbricação entre metodologia e escrita do fazer antropológico. Uma vez que estas marcações são fundantes da discussão proposta no texto, sobre o fazer antropológico diversamente marcado para antropólogas e (não) para antropólogos, decidimos explicitar aqui dois eixos que nortearam nossas discussões neste trabalho de tradução.

O primeiro eixo surgiu logo no título, ao traduzir "reflections from a survivor" por "reflexões de uma sobrevivente", fazendo com que todas as traduções de vítima e sobrevivente acompanhassem a marcação no feminino, em contrapartida com $o$ agressor, traduzido no masculino. Embora não desejássemos cristalizar a ideia de que haveria sempre uma vítima e um agressor, sendo que a própria autora explicita desde a primeira nota de rodapé que não só mulheres podem ser estupradas, tivemos que optar por marcar na tradução, já que seu texto parte dessa sua experiência em campo. O segundo eixo se apresentou também na primeira página, com o subtítulo "Rape and female anthropologists" e se adensa na discussão final proposta pela autora quanto a "identity of anthropologists" como "gender-free" (p.246). Na língua inglesa, ao longo do texto, essa noção neutra da ciência antropológica pode ser representada com "anthropologists" e ao final é revelada pela autora como sendo masculina, O neutro é o masculino, do antropólogo como padrão, daí a necessidade de marcar a antropóloga mulher. Não são questões ausentes na vasta produção dos estudos de gênero, mas decidimos apontá-las aqui como mais um sinal de que gênero estrutura nossas relações, portanto, a linguagem, de forma que a escolha na tradução se relaciona com a discussão antropológica metodológica aqui proposta.

A tradução vem seguida de um comentário feito vinte anos depois de "Rape in the Field" pela própria autora, fruto da movimentação de Thiago Oliveira 
que obteve a autorização para tradução e esse comentário da autora, e o agradecemos muito pela interlocução. Eva Moreno, de forma inesperada e muito bem vinda, abre mão de seu pseudônimo ao nos presentear com esse novo texto que fecha o Especial "Adversidades no Fazer Etnográfico".

Desejamos uma ótima leitura e esperamos que este material contribua para as aulas de graduações em Antropologia e discussões sobre metodologia em campo.

Florbela Ribeiro, Karina Coelho, Letizia Patriarca, Paula Bessa

\section{Referências bibliográficas}

ALMEIDA, Heloisa Buarque de. "Mulher em campo: reflexões sobre a experiência etnográfica." In: Gênero em matizes (Orgs. Heloisa Buarque de Almeida, Rosely Gomes Costa, Martha Celia Ramírez e Érica Renata de Souza) Bragança Paulista, 2002. (Coleção Estudos CDAPH Série História \& Ciências Sociais).

GOLDE, Peggy. Women in the field: anthropological experiences. Berkeley/Los Angeles, University of California Press. 1986.

LANDES, Ruth. A cidade das mulheres. Rio de Janeiro, Civilização Brasileira. 2002.

MORENO, Eva. Rape in the field: reflections from a survivor. In: KULICK, Don; WILLSON, Margaret (eds). Taboo: sex, identity and erotic subjectivity in anthropological fieldwork. London and New York: Routledge.1995. 